\title{
Long-term follow-up of superior gluteal artery perforator flap closure of large myelomeningoceles
}

\author{
Brett A. Whittemore, MD, ${ }^{1}$ Dale M. Swift, MD, ${ }^{2}$ Bradley E. Weprin, MD, ${ }^{2}$ and \\ Frederick J. Duffy Jr., MD³
Departments of ${ }^{1}$ Neurosurgery and ${ }^{2}$ Pediatric Neurosurgery, University of Texas Southwestern Medical Center, Dallas; and ${ }^{3}$ Department of Plastic Surgery, Medical City Hospital, Dallas, Texas

\begin{abstract}
OBJECTIVE Large myelomeningocele defects and poor surrounding tissue quality make some defects particularly difficult to close primarily. This paper describes the superior gluteal artery perforator (SGAP) flap technique for defect closure and long-term clinical outcomes.
\end{abstract}

METHODS The technique for closing a myelomeningocele with an SGAP flap is described. A retrospective chart review was performed on a cohort of 11 patients who underwent closure in this manner.

RESULTS Between 1999 and 2015, 271 myelomeningoceles were closed, 11 of which were SGAP flap closures. The mean defect size was $5.5 \times 7.2 \mathrm{~cm}$. All patients underwent ventriculoperitoneal shunting. There were no cases of CSF infection. Five patients had minor wound issues (small dehiscence or eschar formation) that healed satisfactorily. Two patients had soft-tissue wound infections and required multiple revisions; one patient had multiple severe developmental abnormalities, and the other patient's flap had healed with a thick underlying fat pad 4 months postoperatively. No patients had significant surgical site pain on long-term follow-up.

CONCLUSIONS The SGAP flap technique achieves tension-free closure with vascularized, fat-bearing full-thickness skin. It is useful for closure of large, complex defects, is not associated with chronic pain, and carries a morbidity risk that is comparable to other complex myelomeningocele closure techniques.

https://thejns.org/doi/abs/10.3171/2016.10.PEDS16259

KEY WORDS myelomeningocele closure; superior gluteal artery perforator flap; spina bifida; surgical technique; spine

$\mathrm{M}$ YELOMENINGOCELES are the most common form of neural tube defect, affecting 0.1 to 1 per 1000 live births in the United States. ${ }^{12}$ Since the 1960s, when early closure of these defects was demonstrated to reduce mortality, ${ }^{2}$ closure has become the standard of care. The primary goals of closure are to prevent infection and CSF leakage, preserve neurological function, and reduce late sequelae, such as chronic pain. ${ }^{19}$ The closure of these defects is especially challenging when the defects are large or the surrounding skin and tissue quality are poor.

Multiple techniques for the closure of large defects have been described, including skin grafts, relaxing incisions, random flaps, free flaps, and myocutaneous flaps. ${ }^{1,4,8,13-16,18}$ All aim to create a tension-free skin closure with ample subcutaneous tissue. We previously described the superior gluteal artery perforator (SGAP) flap as an alternative technique for the closure of large defects. ${ }^{5}$ The clinical outcomes for 6 patients who underwent closure using this technique were described. The current paper describes the long-term clinical outcomes for these original 6 patients as well as the outcomes for 5 additional patients who underwent closure with the SGAP flap technique.

\section{Methods}

After obtaining institutional review board approval, we performed a retrospective review of all patients who underwent myelomeningocele closure with the SGAP flap at Children's Medical Center Dallas and Medical City Dallas (the informed consent requirement was waived). These operations were performed by one of 3 pediatric neurosurgeons (D.M.S., B.E.W., and A.V.P.) and a single plastic surgeon (F.J.D.). Demographic data, operative details, clinical course, and long-term follow-up were evaluated.

ABBREVIATIONS SGAP = superior gluteal artery perforator; VAC = vacuum-assisted closure; VP = ventriculoperitoneal.

SUBMITTED May 9, 2016. ACCEPTED October 19, 2016.

INCLUDE WHEN CITING Published online January 20, 2017; DOI: 10.3171/2016.10.PEDS16259. 


\section{Operative Technique}

After induction of general anesthesia, the patient is positioned prone on the operating table. The superior gluteal artery perforators are identified using Doppler ultrasound, and the flap is demarcated (Figs. 1A and 2A). The neurosurgeon begins by carefully dissecting the neural tissue and dura. The neural placode is trimmed of epithelial and nonviable tissue and then is imbricated with fine absorbable monofilament suture. The dura is closed using absorbable monofilament suture. The plastic surgeon then incises and elevates the flap based on the dominant perforator. The pedicled flap is rotated into the desired posi- tion. If the location, width, and viability of the isthmus of skin between the myelomeningocele defect and the gluteal donor site is favorable, the flap is tunneled beneath this isthmus; otherwise, the isthmus is divided. The flap is then inset (Figs. 1B, 1C, 2B, and 2C). The full-thickness skin graft is closed in layers after freshening the margins of the cutaneous defect. This closure is generally tension free. The donor site is closed (Figs. 1D and 2D). Postoperatively, the infant is kept prone for approximately 7 days or longer, depending on wound healing and the need for a shunt. The procedure is graphically illustrated in Fig. 1, with correlating photographs in Fig. 2.
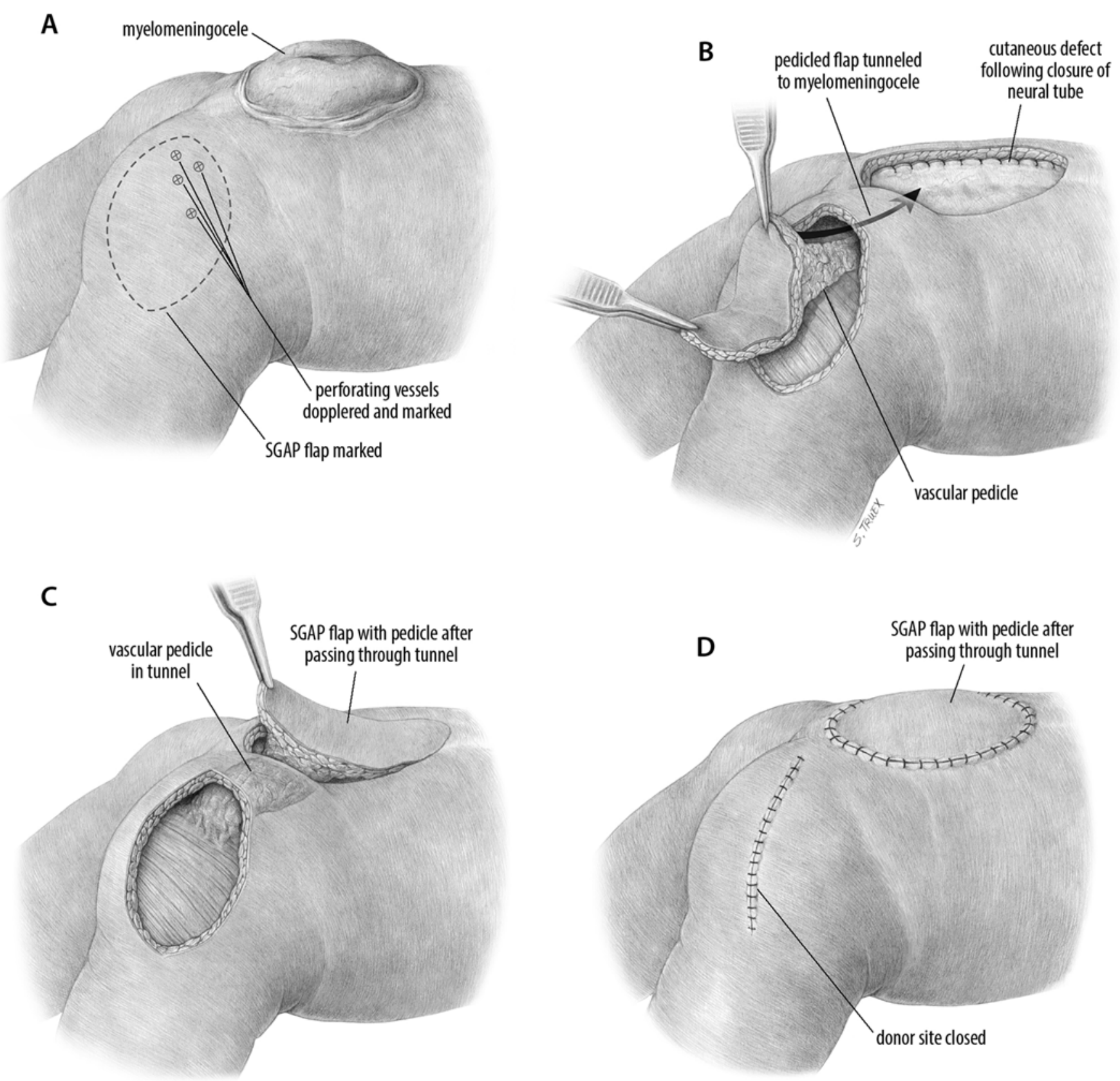

FIG. 1. Steps for closure of a large myelomeningocele with the superior gluteal artery perforator (SGAP) flap. Copyright Department of Neurological Surgery, UT Southwestern. Published with permission. 


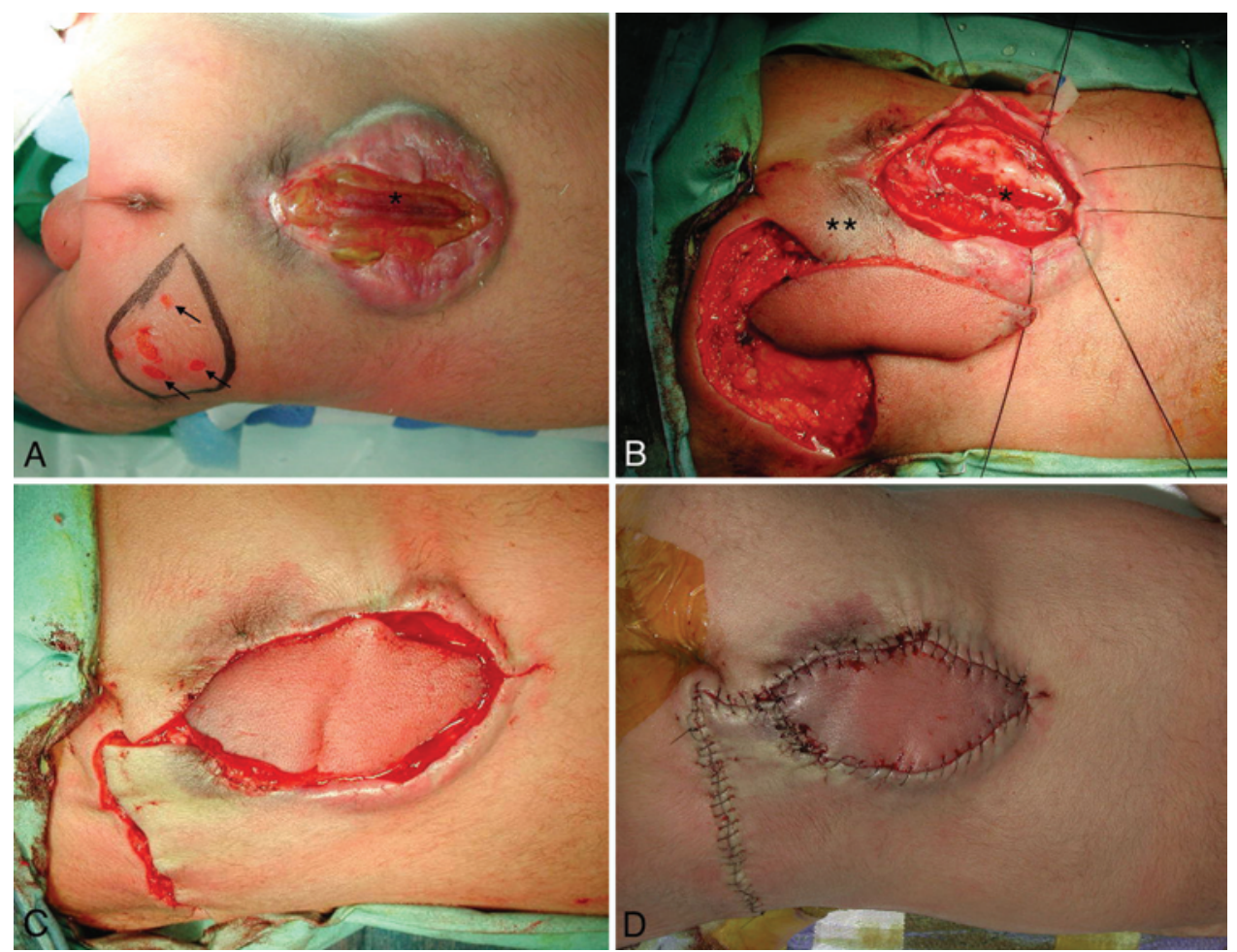

FIG. 2. A: Perforators are marked using Doppler ultrasound (arrows) and the SGAP flap is demarcated; neural tube $\left(^{*}\right)$. B: The neural tube is imbricated, the dura is closed $\left(^{*}\right)$, and the flap is mobilized; isthmus of skin between the gluteal donor site and the myelomeningocele defect $\left({ }^{* *}\right)$. C: The flap is rotated into position and tunneled if the isthmus is left undivided. D: The flap is sutured into place. Figure is available in color online only.

\section{Results}

Between December 1999 and January 2015, 271 thoraco-lumbo-sacral myelomeningoceles were closed at Children's Medical Center Dallas and Medical City Dallas Hospital. For large lumbosacral defects for which a complicated closure was anticipated, consultation with the plastic surgery team was obtained. The plastic surgery service participated in approximately $17 \%$ of closures, and in 11 patients the SGAP flap was used. For SGAP closures, the mean defect size was $5.5 \times 7.2 \mathrm{~cm}$. The mean gestational age at birth was 37 weeks. The isthmus of skin between the gluteal donor site and the myelomeningocele defect was divided in the majority of cases; 3 flaps were tunneled beneath the isthmus. The decision to tunnel or rotate the flap depended on the anatomical factors described above (location, width, and viability of skin isthmus). There was no clear advantage for tunneling versus rotating the flap. In this cohort of 11 patients, all underwent ventriculoperitoneal (VP) shunting from 3 days to 6 weeks after myelomeningocele repair. For comparison, of the 271 total myelomeningocele closures, $78 \%$ underwent VP shunt placement within 3 months of birth. There were no cases of CSF infection. Five of the patients had minor wound issues, such as small areas of dehiscence or eschar formation. None of these 5 patients required surgical revision, and ultimately all healed satisfactorily. One patient developed a subcutaneous fluid collection, which was percutaneously aspirated and subsequently resolved after CSF diversion. Another patient exhibited a small pre- sumed CSF leak that also resolved after placement of a VP shunt. The average follow-up was 9.7 years, ranging from 15 months to 15.3 years, and 10 of the 11 patients had at least 2 years of follow-up. Details of each patient are included in Table 1.

Two patients developed necrosis and subsequent infection of a portion of the SGAP flap and required surgical wound revision. One patient, whose defect was $6 \times 8 \mathrm{~cm}$, developed necrosis of approximately $60 \%$ of the flap at the cephalad end. This patient had a constellation of severe developmental abnormalities, including intrauterine growth retardation, diffuse cerebral cortical dysplasia with calcifications, seizures, and premature birth (birth weight 1200 g). She underwent multiple surgical treatments, including tracheostomy, Nissen fundoplication, gastric tube, and anal cerclage for rectal prolapse. The SGAP flap was not large enough to cover the entire defect, and the cephalad part of the defect could not be closed primarily. The intent at the time of the initial closure was to return to the operating room for subsequent stages. The patient returned to the operating room for wound debridement at 2 and 16 days postoperatively. Integra Dermal Regeneration Template (Integra LifeSciences Corp.) and Apligraf (Organogenesis, Inc.) skin substitutes were applied as well as a wound vacuum-assisted closure (VAC). This patient also developed cellulitis at the gluteal donor site. The SGAP flap and donor site incisions eventually healed completely without CSF infection. A second patient also developed partial necrosis of the SGAP flap, which required 2 surgi- 
TABLE 1. Data for 11 patients who underwent myelomeningocele closure with an SGAP

\begin{tabular}{|c|c|c|c|c|c|c|c|}
\hline $\begin{array}{l}\text { Case } \\
\text { No. }\end{array}$ & $\begin{array}{l}\text { Length of } \\
\text { FU (yrs) }\end{array}$ & $\begin{array}{l}\text { Defect } \\
\text { Width } \\
(\mathrm{cm})\end{array}$ & $\begin{array}{l}\text { Defect } \\
\text { Height } \\
(\mathrm{cm})\end{array}$ & $\begin{array}{l}\text { Gestational } \\
\text { Age at } \\
\text { Birth (wks) }\end{array}$ & $\begin{array}{c}\text { Chiari II } \\
\text { Decompression }\end{array}$ & Postop Issues & Comorbidities \\
\hline 1 & 13.4 & 5 & 7 & 26 & Yes & & Imperforate anus, g-tube, seizures \\
\hline 2 & 12.3 & 4.5 & 6 & "Full term" & No & $\begin{array}{l}\text { 4-mm superficial sloughing at } 2 \text { wks postop, } \\
\text { healed well }\end{array}$ & \\
\hline 3 & 13.5 & 4.5 & 5.5 & 36 & No & $\begin{array}{l}\text { Small area of dehiscence healed well after } \\
\text { application of Steri-Strips }\end{array}$ & \\
\hline 4 & 13.1 & 5 & 8 & "Full term" & Yes & $\begin{array}{l}\text { Small area of superior wound breakdown, } \\
\text { healed well }\end{array}$ & $\begin{array}{l}\text { Cerebellar \& brainstem hypopla- } \\
\text { sia, g-tube, epilepsy, bilat hernia } \\
\text { repairs, developmental delay }\end{array}$ \\
\hline 5 & 13.1 & "Large" & & 40 & Yes & & Dysphagia, g-tube, BiPAP use \\
\hline 6 & 9.7 & 3.5 & 7 & 39 & No & & Undescended testes \\
\hline 7 & 9.0 & 6 & 8 & 37 & Yes & $\begin{array}{l}2 \text { wound revisions, wound VAC, cellulitis at } \\
\text { gluteal site }\end{array}$ & $\begin{array}{l}\text { Intrauterine growth retardation } \\
\text { (birth weight } 1200 \mathrm{~g} \text { ), tracheo- } \\
\text { broncomalacia, tracheostomy, } \\
\text { home ventilator, g-tube, rectal } \\
\text { prolapse, anal cerclage, epi- } \\
\text { lepsy, Chiari decompression }\end{array}$ \\
\hline 8 & 8.3 & 9 & 10 & 40 & No & Superior eschar, healed well & \\
\hline 9 & 7.9 & 5 & 6 & 40 & No & $\begin{array}{l}2 \text { wound revisions, wound VAC placement, } \\
\text { superior dehiscence, eventually healed w/ } \\
\text { ample redundant tissue }\end{array}$ & $\begin{array}{l}\text { Developmental delay, seizures, } \\
\text { g-tube }\end{array}$ \\
\hline 10 & 3.3 & 8 & 8.5 & 38 & No & $\begin{array}{l}\text { Wound VAC initially placed on inferior edge of } \\
\text { incision, eschar formed, healed by second- } \\
\text { ary intention; subcutaneous fluid collection } \\
\text { formed, tapped } 1 \text { wk postop, ventriculos- } \\
\text { tomy placed followed by VP shunt }\end{array}$ & $\begin{array}{l}\text { Grade I germinal matrix hemor- } \\
\text { rhage, hydronephrosis }\end{array}$ \\
\hline 11 & 1.3 & 4 & 6 & 37 & No & & \\
\hline
\end{tabular}

BiPAP = bilevel positive airway pressure; FU = follow-up; g-tube = gastrostomy tube.

All patients underwent ventriculoperitoneal shunt implantation.

cal revisions with application of Integra and Apligraf as well as a wound VAC. By 4 months of age the flap had healed well and the underlying fat pad was full.

Four patients were treated surgically for symptomatic Chiari malformations (ages 10 weeks to 2.5 years). As the children aged, there were no recorded instances of chronic severe low-back pain or progression of symptoms of a tethered spinal cord. A fully healed SGAP closure is shown in Fig. 3. A sagittal T1-weighted MR image obtained 22 months after an SGAP closure is shown in Fig. 4.

\section{Discussion}

The SGAP flap is well described in nonneurosurgical contexts, including treatment of sacral pressure ulcers ${ }^{11,20}$ and reconstructive breast surgery. ${ }^{4}$ We first described application of the SGAP flap to neonatal myelomeningocele closure in $2004 .{ }^{5}$ Since then, its successful application to this problem and modification by other surgeons has been reported. ${ }^{7,18}$ The primary indication for its use is a large defect $\left(>24 \mathrm{~cm}^{2}\right)$ that would be difficult to close without a complex reconstructive approach. In our series, major wound complications requiring revision surgery occurred in $18 \%$ ( 2 of 11) of patients. This is comparable to published rates of SGAP flap necrosis in adult patients ${ }^{20}$ and to revision rates of complicated myelomeningocele closures with plastic surgery assistance $(10 \%) .^{3}$ In our series, flap breakdown usually occurred at the cranial-most end of the flap. The flaps were designed to maximize the extent of coverage in this direction and minimize tension on this part of the skin closure.

Most reported techniques for closure of large myelomeningocele defects advance intact lateral tissues medially, resulting in the skin suture line overlying the dural closure. Even with medial advancement of latissimus dorsi and gluteus maximus myocutaneous flaps, the cutaneous suture line generally lies close to the dural closure. ${ }^{15}$ This reconstruction technique not only provides little tissue coverage to mitigate CSF leakage, but fails to develop subcutaneous fat normally. In contrast, the design of the SGAP flap technique causes the central region overlying the dura to be the most robust rather than the weakest part of the closure. As the flap ages, the midline region actually becomes quite plump (Fig. 3). We have observed no tenderness over the midline as is our common observation in many other myelomeningocele patients.

A gluteal propeller flap is a variation of the SGAP flap and includes rotation of a portion of the superior gluteal musculature. ${ }^{18}$ We believe that the SGAP flap provides 


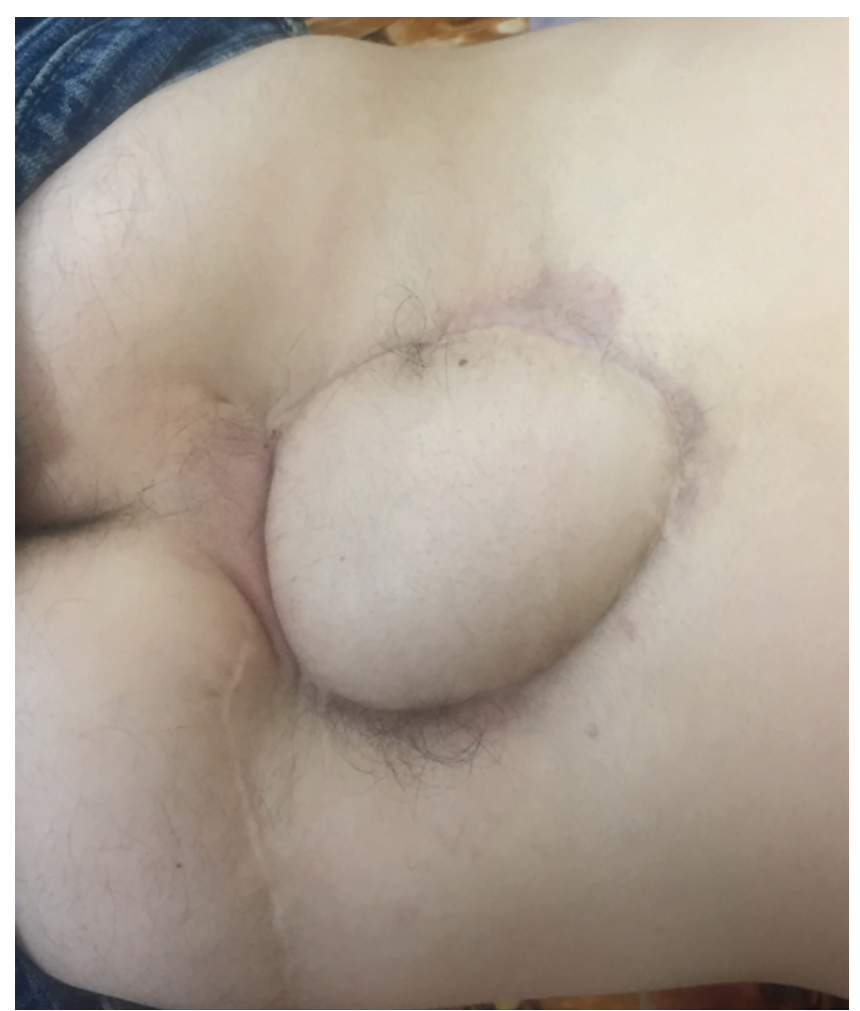

FIG. 3. Case 1. Healed SGAP flap, 15.3 years after surgery. Note the thick pad of subcutaneous tissue at the midline. Figure is available in color online only.

sufficient subcutaneous tissue coverage such that inclusion of the musculature is unnecessary. In fact, one distinct advantage of the SGAP flap is that it leaves the underlying gluteal musculature intact, thereby allowing for future wound revision options as well as preservation of functional muscle in nonparaplegic patients. Options for future wound revisions in this patient population are a relevant consideration. For example, a long-term retrospective review found that sacral pressure ulcers in myelomeningocele patients were most commonly repaired after 12 years of age. ${ }^{9}$

All patients who received a VP shunt did so based on the findings, clinical and/or radiographic, that were concerning for symptomatic hydrocephalus. We use rapid or abnormal head growth, sutural diastasis, progressive enlargement of ventricles on serial imaging studies, or feeding intolerance as criteria for shunt placement. The $100 \%$ shunt rate in our patients who underwent closure with the SGAP flap is higher than the general incidence of symptomatic hydrocephalus in myelomeningocele patients (the overall shunt rate of all myelomeningocele patients at our institution is 78\%), but this is most likely due to the small sample size of our cohort rather than a difference in our indications for shunt placement.

Nearly all children with myelomeningoceles have a radiographically tethered spinal cord; however, only 10\%-30\% become symptomatic. ${ }^{6}$ Common presenting symptoms are worsening back pain at the myelomeningocele closure site, spasticity, worsening lower-extremity motor function, and progressive scoliosis..$^{10,17}$ Whether the

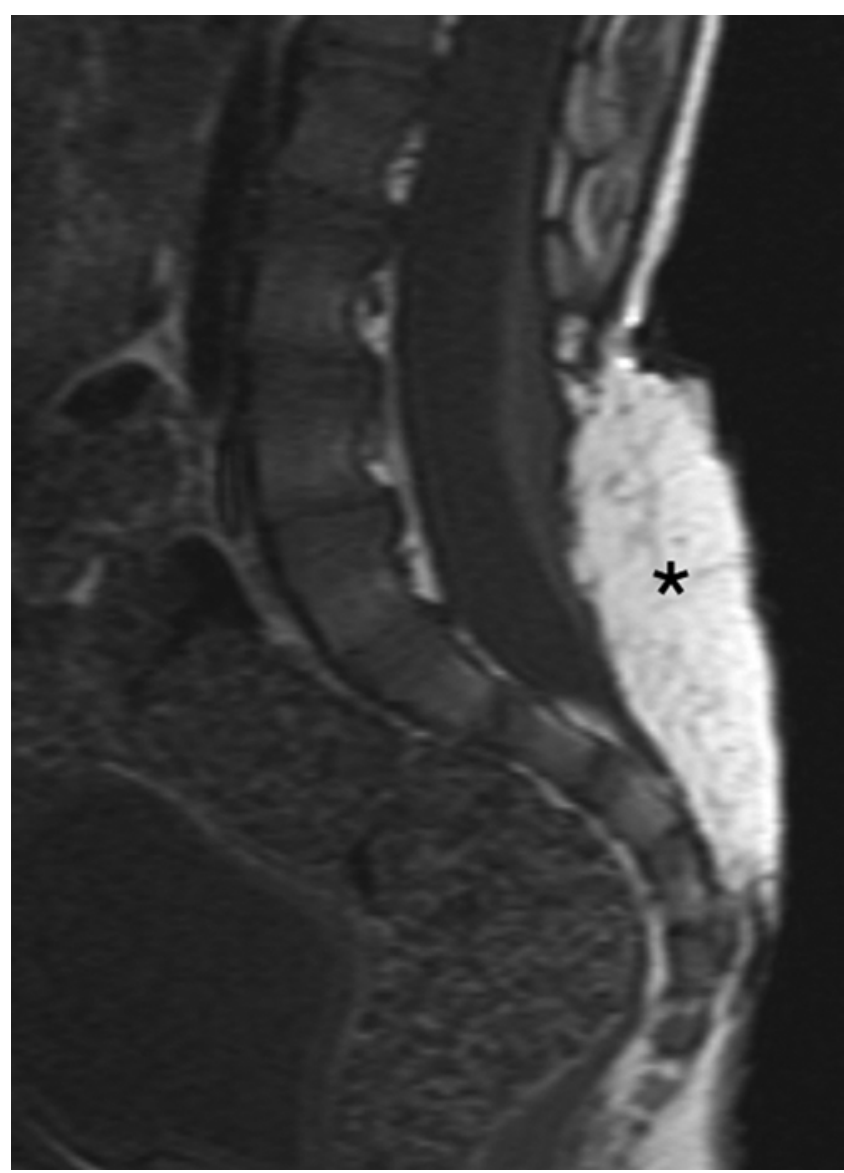

FIG. 4. Case 4. Sagittal T1-weighted MR image obtained 22 months after SGAP closure; thick subcutaneous fat pad $\left({ }^{*}\right)$.

closure method affects the development of tethered cord symptoms is not known. It is interesting that, to date, no patient who underwent closure with the SGAP flap has developed clinical manifestations that are concerning for tether. Should it become necessary to perform a tethered cord release or to expose the distal spine, we would plan to open the side of the incision opposite the SGAP flap donor site to avoid the vascular pedicle. We would then extend the skin incision above and below the flap in the midline, taking care to leave a generous layer of subcutaneous fat superficial to the plane opened over the dura to preserve the vascular supply to the skin.

Back pain is a common complaint in this patient population, especially as patients age. It is our common observation that myelomeningocele patients often have tenderness at the closure site where the scar is taut and subcutaneous fat is thin or absent. Interestingly, our patients who underwent closure with the SGAP flap did not exhibit tenderness at the closure site on follow-up examinations. That the SGAP flap closure method may decrease the incidence of chronic pain by providing substantial fat coverage of the dura and minimizing adhesion to the overlying skin is a concept that will require systematic investigation.

\section{Conclusions}

The SGAP flap technique is a useful although techni- 
cally challenging technique for closure of large lumbosacral myelomeningoceles. It achieves tension-free placement of a vascularized soft-tissue layer directly over the dural closure and results in redundant tissue covering the myelomeningocele defect once the wound has healed. It preserves gluteal musculature in nonparaplegic patients and allows for future wound revision options in this population that is prone to developing pressure ulcers. Our series demonstrates that this procedure can be successfully performed in newborns. Because of the procedure's relative complexity and higher potential morbidity with wound healing, it should be reserved for defects that are difficult to close.

\section{Acknowledgments}

We would like to thank Suzanne Truex, medical illustrator, for her beautiful illustration of the steps of the surgical procedure. In Methods, A.V.P. refers to neurosurgeon Angela V. Price, MD.

\section{References}

1. Bagłaj M, Ladogórska J, Rysiakiewicz K: Closure of large myelomeningocoele with Ramirez technique. Childs Nerv Syst 22:1625-1629, 2006

2. Brocklehurst G, Gleave JR, Lewin W: Early closure of myelomeningocele, with special reference to leg movement. BMJ 1:666-669, 1967

3. de Chalain TMB, Cohen SR, Burstein FD, Hudgins RJ, Boydston WR, O'Brien MS: Decision making in primary surgical repair of myelomeningoceles. Ann Plast Surg 35:272-278, 1995

4. DellaCroce FJ, Sullivan SK: Application and refinement of the superior gluteal artery perforator free flap for bilateral simultaneous breast reconstruction. Plast Reconstr Surg 116:97-105, 2005

5. Duffy FJ Jr, Weprin BE, Swift DM: A new approach to closure of large lumbosacral myelomeningoceles: the superior gluteal artery perforator flap. Plast Reconstr Surg 114:1864-1870, 2004

6. Hudgins RJ, Gilreath CL: Tethered spinal cord following repair of myelomeningocele. Neurosurg Focus 16(2):E7, 2004

7. Kucuker I, Sezgin B, Tuncer S, Ayhan S: Superior gluteal artery perforator flap for meningomyelocele defect: a saviour when other options vanish. Indian J Plast Surg 47:149-150, 2014

8. Luce EA, Stigers SW, Vandenbrink KD, Walsh JW: Splitthickness skin grafting of the myelomeningocele defect: a subset at risk for late ulceration. Plast Reconstr Surg 87:116-121, 1991

9. Marreiros H, Loff C, Calado E: Who needs surgery for pediatric myelomeningocele? A retrospective study and literature review. J Spinal Cord Med 38:626-640, 2015

10. McLone DG: Continuing concepts in the management of spina bifida. Pediatr Neurosurg 18:254-256, 1992

11. Meltem C, Esra C, Hasan F, Ali D: The gluteal perforator- based flap in repair of pressure sores. Br J Plast Surg 57:342-347, 2004

12. Perry VL, Albright AL, Adelson PD: Operative nuances of myelomeningocele closure. Neurosurgery 51:719-724, 2002

13. Ramasastry SS, Cohen M: Soft tissue closure and plastic surgical aspects of large open myelomeningoceles. Neurosurg Clin N Am 6:279-291, 1995

14. Ramirez OM, Orlando JC, Hurwitz DJ: The sliding gluteus maximus myocutaneous flap: its relevance in ambulatory patients. Plast Reconstr Surg 74:68-75, 1984

15. Ramirez OM, Ramasastry SS, Granick MS, Pang D, Futrell JW: A new surgical approach to closure of large lumbosacral meningomyelocele defects. Plast Reconstr Surg 80:799809, 1987

16. Roche NA, Van Landuyt K, Blondeel PN, Matton G, Monstrey SJ: The use of pedicled perforator flaps for reconstruction of lumbosacral defects. Ann Plast Surg 45:7-14, 2000

17. Sarwark JF, Weber DT, Gabrieli AP, McLone DG, Dias L: Tethered cord syndrome in low motor level children with myelomeningocele. Pediatr Neurosurg 25:295-301, 1996

18. Schmidt VJ, Horch RE, Dragu A, Beier JP, Eyüpoglu IY, Hirsch A, et al: Myocutaneous propeller flap based on the superior gluteal artery (SGA) for closure of large lumbosacral meningomyelocoele defects: a case report. J Plast Reconstr Aesthet Surg 65:521-524, 2012

19. Tamaki N, Shirataki K, Kojima N, Shouse Y, Matsumoto S: Tethered cord syndrome of delayed onset following repair of myelomeningocele. J Neurosurg 69:393-398, 1988

20. Verpaele AM, Blondeel PN, Van Landuyt K, Tonnard PL, Decordier B, Monstrey SJ, et al: The superior gluteal artery perforator flap: an additional tool in the treatment of sacral pressure sores. Br J Plast Surg 52:385-391, 1999

\section{Disclosures}

The authors report no conflict of interest concerning the materials or methods used in this study or the findings specified in this paper.

\section{Author Contributions}

Conception and design: Swift, Weprin, Duffy. Acquisition of data: all authors. Analysis and interpretation of data: all authors. Drafting the article: Whittemore. Critically revising the article: all authors. Reviewed submitted version of manuscript: all authors. Study supervision: Swift, Weprin.

\section{Supplemental Information \\ Previous Presentations}

A poster with the content of this paper in abstract form was presented at the AANS/CNS Section on Pediatric Neurological Surgery, December 8-11, 2015, in Seattle, Washington.

\section{Correspondence}

Brett A. Whittemore, Department of Neurosurgery, UT Southwestern, 5323 Harry Hines Blvd., Dallas, TX 75390. email: bawhitt@gmail.com. 